\title{
Explaining variance in health literacy among people with type 2 diabetes: the association between health literacy and health behaviour and empowerment
}

Hanne Søberg Finbråten ${ }^{1,2^{*}}$ (D, , Øystein Guttersrud ${ }^{3}$, Gun Nordström ${ }^{1}$, Kjell Sverre Pettersen ${ }^{4}$, Anne Trollvik ${ }^{1}$ and Bodil Wilde-Larsson ${ }^{1,2}$

\begin{abstract}
Background: To reflect the health literacy (HL) skills needed for managing type 2 diabetes (T2DM) in everyday life, $\mathrm{HL}$ in people with T2DM should be measured from a broader perspective than basic skills, such as proficiency in reading and writing. The HLS-Q12, based on the European Health Literacy Survey Questionnaire (HLS-EU-Q47), assesses four cognitive domains across three health domains. International studies on people with T2DM show inconsistent results regarding the association between $\mathrm{HL}$ and general health and the association between $\mathrm{HL}$ and glycaemic control. Moreover, knowledge is needed related to the link between $\mathrm{HL}$ and empowerment for those with T2DM. The aims of this study were to examine the association between i) $\mathrm{HL}$ and general health and diabetes outcomes, ii) $\mathrm{HL}$ and health behaviours and iii) $\mathrm{HL}$ and empowerment in people with T2DM.
\end{abstract}

Methods: During March and April 2015, 388 adults with T2DM responded to a paper-and-pencil self-administered questionnaire. A sequential multiple regression analysis was applied to explore the association between $\mathrm{HL}$, as measured by the HLS-Q12, and health conditions, HbA1c, health behaviours and empowerment.

Results: For people with T2DM, higher levels of HL were associated with higher levels of education, better overall health conditions and higher self-perceived empowerment. No empirical evidence strengthening either the link between $\mathrm{HL}$ and glycaemic control or the link between $\mathrm{HL}$ and health behaviours was found.

Conclusions: The independent variables education level, overall health condition and empowerment explained about one-third of the total observed variance in $\mathrm{HL}$.

Keywords: Empowerment, General health, Health behaviour, Health literacy, HLS-Q12, Sequential multiple regression analysis, Type 2 diabetes

\section{Background}

Health literacy (HL) is an essential individual competence necessary for dealing with health information provided, making appropriate health-related decisions and managing health in different situations [1]. Sørensen et al. [2] defined HL as follows: Health literacy is linked

\footnotetext{
* Correspondence: hanne.finbraten@inn.no

'Department of Health and Nursing Sciences, Faculty of Social and Health Sciences, Inland Norway University of Applied Sciences, PO Box 400, N-2418 Elverum, Norway

2Department of Health Sciences, Faculty of Health, Science and Technology, Nursing science, Karlstad University, SE-65188 Karlstad, Sweden

Full list of author information is available at the end of the article
}

to literacy and entails people's knowledge, motivation and competence to access, understand, appraise, and apply health information in order to make judgments and take decisions in everyday life concerning healthcare, disease prevention and health promotion to maintain or improve quality of life during the life course (p. 3). Having sufficient HL might be more important than ever before because people are expected to participate in health decisions and to take responsibility for their own health despite more complicated health problems and the need to navigate a more complex health system [3].

(c) The Author(s). 2020 Open Access This article is distributed under the terms of the Creative Commons Attribution 4.0 International License (http://creativecommons.org/licenses/by/4.0/), which permits unrestricted use, distribution, and reproduction in any medium, provided you give appropriate credit to the original author(s) and the source, provide a link to the Creative Commons license, and indicate if changes were made. The Creative Commons Public Domain Dedication waiver (http://creativecommons.org/publicdomain/zero/1.0/) applies to the data made available in this article, unless otherwise stated. 
Studies have linked poor diabetes knowledge [4-6], poor glycaemic control [5, 7-9] and diabetic retinopathy [7] in people with type 2 diabetes (T2DM) to low HL. Using a modified version of the Functional, Communicative and Critical Health Literacy scale (FCCHL) [10], Finbråten et al. [11] found that lower HL is linked with poorer self-reported general health in people with T2DM. Similarly, Al Sayah, Qiu and Johnson [12] found that low HL is associated with lower health-related 'quality of life' measures in people with T2DM. However, neither the links between low HL and diabetes outcomes, such as poor glycaemic control [13-15], nor the links between HL and other self-reported health-related measures, such as general health and quality of life, are consistent [13, 16, 17]. Based on their systematic review of reviews, Caruso et al. [18] also revealed gaps in knowledge about the relations between $\mathrm{HL}$ and health outcomes. Thus, further studies are needed.

The prevalence of T2DM is increasing worldwide, and T2DM is strongly associated with lifestyle and health behaviours [19]. Physical activity has a beneficial effect on blood glucose levels, whereas physical inactivity, the use of tobacco and high alcohol consumption could increase the risk for complications, such as cardiovascular diseases [19, 20]. Despite T2DM having been associated with health behaviours, such as low physical activity [19], few studies have investigated the association between HL and health behaviours in people with T2DM. Some studies have linked low HL to physical inactivity, but these studies did not differentiate between type 1 and type 2 diabetes $[4,21]$. The associations between $\mathrm{HL}$ and smoking behaviours and alcohol consumption are not strongly supported [22-26].

HL may facilitate the self-management of T2DM [27], active participation in diabetes treatment [28] and interactive communication with health professionals. 'Empowerment'-individuals' ability to make decisions and to maintain control over their personal lives [29]—refers to selfmanagement and control over one's own health. Empowerment has become a major goal in health communication [30] and is also viewed as a goal of HL itself [31]. Theoretical relationships have been established between $\mathrm{HL}$ and empowerment [1, 2, 32], where high HL is believed to increase opportunities for autonomy and empowerment in health-related decision-making [32, 33]. Wang et al. [27] emphasised the importance of HL and empowerment for self-management in people with T2DM. However, the association between $\mathrm{HL}$ and empowerment in people with T2DM has not yet been fully explored.

Research on the links between HL and health outcomes in general and between HL and health outcomes related to T2DM specifically have measured $\mathrm{HL}$ as a set of basic skills in clinical settings, such as numeracy and reading, which one might refer to as 'functional' HL.
Examples of such measurement scales are the Test of Functional Health Literacy in Adults (TOFHLA) [34] (or the S-TOFHLA [35]), the Rapid Estimate of Adult Literacy in Medicine (REALM) [36] and Chew's 'brief questions to identify patients with inadequate HL' [37]. However, people with T2DM require proficiencies that surpass basic skills if they are to utilise health information in their everyday management of the disease. The relationship between HL and health outcomes in general and between health outcomes of T2DM specifically should be further explored using instruments that capture the broader aspects of $\mathrm{HL}$, such as the capacity to find, understand, evaluate and apply health information across different contexts; health care, disease prevention and health promotion. These capacities are related to the definition of HL used in this article. The European Health Literacy Survey Questionnaire (HLS-EU-Q47) was developed on the basis of this framework [2, 38, 39]. However, Finbråten et al. [40] and Huang et al. [41] have revealed several psychometric weaknesses of the HLSEU-Q47 when validated in people with T2DM and in people with stroke, respectively. The newly developed and shortened version of this instrument, the HLS-Q12, which has enhanced psychometric properties [42, 43], was well-suited for HL screenings in the study sample of people with T2DM.

Against this background, the aims of this study were to examine the association between i) $\mathrm{HL}$ and general health and diabetes outcomes, ii) HL and health behaviours and iii) HL and empowerment in people with T2DM

\section{Methods}

Study design

This cross-sectional study was conducted based on data from adults with T2DM recruited from the Norwegian Diabetes Association (NDA)-a member of the International Diabetes Federation. NDA is an independent organisation that aims to serve people with diabetes, and membership is voluntary.

\section{Participants and data collection}

According to the Norwegian Prescription Database 149, 057 people were pharmacologically treated for T2DM in 2014 ( $87 \%$ of these had an age of 50 or older and $43 \%$ were females) [44]. At the time of sampling, 16,754 people with T2DM (average age 68 years and 53\% females) were members of the NDA (Norwegian Diabetes Association, personal communication, 7 May 2015). After careful instructions from the researchers, the NDA drew a random sample of 999 people with T2DM from the 7655 members residing in nine of Norway's 19 counties (members from the other counties participated in a pilot study that was conducted 1 year prior). All parts of 
the country were represented in the current study. An inclusion criteria was being diagnosed with T2DM. Further, the NDA was asked to draw a random sample from the member list, but make sure that the gender and age composition of the sample matched the distribution of gender and age of the members in the selected counties. Assuming $80 \%$ power, a small to medium effect size and having six predictors, a sample size of 142 would be sufficient for regression analysis. When using a sample size calculator and considering a confidence level of $95 \%$ and a confidence interval of 5 , a sample of 376 is recommended. Thus, invitation was sent to 999 people, expecting that about one third should return a completed questionnaire.

Using a self-administrated paper-and-pencil questionnaire, the data were collected between March and April 2015. As the questionnaire was distributed via regular mail, two questionnaires were returned due to unknown addresses. Responses were received from 406 individuals. Eighteen respondents who reported type 1 diabetes were excluded as they did not meet the inclusion criteria. Furthermore, 31 individuals reported health conditions that were incompatible with responding to the questionnaire and were consequently excluded. Hence, the analyses were based on responses from 388 individuals (response rate $41 \%$ [388/948]).

In our sample, just over half of the 388 respondents were men (Table 1 ). The average age was 73 years. Just below one-third had compulsory comprehensive school as their highest completed education, and about the same fraction had completed education at a university or university college level. The majority of the respondents reported fairly good to very good general health.

\section{Measures}

HL was measured using the HLS-Q12 instrument developed by Finbråten et al. [42]. The respondents were asked to report demographic variables (gender, age and education level), health behaviours (physical activity, alcohol consumption and tobacco use), general health condition ('How is your health in general?'), items intended to be indicators of empowerment and their latest measured glycated haemoglobin (HbA1c) level. In Norway, HbA1c is measured at least twice a year in people with T2DM [45]. They were also asked whether they had communicated with a registered nurse about health-related issues during the past 12 months.

\section{Health literacy}

Using the 12-item HLS-Q12 [42], which has been validated in the Norwegian population [42, 43] and for Norwegians with T2DM (see below) [43], HL was measured across the four cognitive domains (access, understand, appraise and apply health information) and three health
Table 1 Sample characteristics $(n=388)$

\begin{tabular}{|c|c|}
\hline \multicolumn{2}{|l|}{ Characteristic } \\
\hline Gender & $n(\%)$ \\
\hline Male & 207 (53) \\
\hline Female & $165(43)$ \\
\hline Missing & $14(4)$ \\
\hline Education & $n(\%)$ \\
\hline Compulsory comprehensive school & $111(29)$ \\
\hline Upper secondary school & $84(22)$ \\
\hline University/university college & $118(30)$ \\
\hline Other & $51(13)$ \\
\hline Missing & $22(6)$ \\
\hline General health status & $n(\%)$ \\
\hline Very good & $19(5)$ \\
\hline Good & $150(39)$ \\
\hline Fairly good & $146(38)$ \\
\hline Bad & 57 (15) \\
\hline Very bad & $7(2)$ \\
\hline Missing & $7(2)$ \\
\hline \multicolumn{2}{|l|}{ Age } \\
\hline Mean $(s d)$ & $73(8.6)$ \\
\hline Median & 74 \\
\hline Lowest-highest & $50-92$ \\
\hline Missing & 13 \\
\hline \multicolumn{2}{|l|}{$\mathrm{HbA} 1 \mathrm{c}(\%)^{a}$} \\
\hline Mean $(s d)$ & $7.29(0.98)$ \\
\hline Lowest-highest & $5.4-13.0$ \\
\hline Missing & $76(20)$ \\
\hline
\end{tabular}

domains (health care, disease prevention and health promotion) of the model developed by Sørensen et al. [2] The 12-item HLS-Q12 scale, for which each cell of this $4 \times 3$ matrix of $\mathrm{HL}$ is represented by one item, has a 4point rating scale; very difficult (1), difficult (2), easy (3) and very easy (4), where the higher score sums indicate higher HL proficiencies. The additional response category 'don't know' was recoded as 'systematic missing' during the analyses. Using the scoring model $0-3$, the HLS-Q12 raw score sums represent a so-called sufficient statistic for the unidimensional partial credit Rasch model [46, 47]. Using a confirmatory factor analysis (CFA) and treating the data as categorical (Robust Maximum Likelihood [RML] and Diagonally Weighted Least Squares [DWLS] estimators), it was found that the HLS-Q12 data also displayed acceptable 'goodness-of-fit' indexes. 
When applied to people with T2DM, the HLS-Q12 is sufficiently reliable with high reliability indexes (person separation index estimated to 0.847 using the RUMM2030 statistical package [48] and Coefficient $H$ estimated to 0.923). All 12 items conformed well to the partial credit parameterisation of the unidimensional Rasch model, and all items had ordered response categories / no reversed Rasch-Andrich thresholds. At the overall level, the HLS-Q12 is sufficiently unidimensional (lower binominal 95\% CI proportion of 0.04) with no significantly locally dependent items (cf. 'response dependency') and no items displaying 'differential item functioning' for available person factors [43].

After applying CFA using LISREL9.3 software [49], the HLS-Q12 displayed acceptable goodness-of-fit (GOF) indexes (normed Satorra-Bentler chi square of 1.67, standardised root mean square residual [SMSR] of 0.066 , comparative fit index [CFI] of 0.976 and a root mean square error of approximation [RMSEA] of 0.132). The item communalities varied between 0.36 and 0.65 with an average value of 0.48 [43].

\section{Health behaviour}

Health behaviour was reported using single items related to physical activity, tobacco use and alcohol consumption. These items were developed based on similar items of the HLS-EU-Q47 [38]. The participants reported their physical activity by responding to the single item 'How often have you been physically active for at least 30 minutes during the last 30 days?', which had four response categories: none of the days (1), some of the days (2), some days every week (3) and every or almost every day (4). Respondents were classified as physically active if they reported being physically active 'every or almost every day'. The respondents reported their tobacco use by answering the single item 'How would you best describe your use of tobacco (such as cigarettes, cigars and tobacco pipes)?', which had four response categories: smoke every day (1), smoke now and then (2), former smoker (3) and never smoked (4). Those who answered that they were former smokers or had never smoked were all classified as nonsmokers. Alcohol consumption was reported by responding to the single item 'How often did you drink alcohol during the last 30 days?' with the response categories: none of the days (1), once (2), two-three times (3), once a week (4), two-three times a week (5), four-six times a week (6) and every day (7). Those who answered 'none of the days' were classified as non-consumers. For all items, the response category 'do not want to answer' was offered and later recoded as 'systematic missing'.

\section{Empowerment-related indicators}

Empowerment-related indicators were measured using four self-developed items. The items were developed based on the Diabetes Empowerment Scale [50], considering the World Health Organisation's definition of individual empowerment [29] and the aspects of patient empowerment as described by Schulz and Nakamoto [1, 51]. The four items asked how difficult or easy it is to: 1) take control of one's own health in daily life, 2) implement goals related to one's own health, 3) take responsibility for one's own physical and mental health by being physical active, eating healthily and being social and 4) participate actively in health communication with health professionals by asking questions and prompting a plan of action for one's own health needs. The items were used as a proxy for empowerment and had a four-point response scale: very difficult (1), difficult (2), easy (3) and very easy (4), where higher scores indicated higher empowerment.

\section{Data analysis}

When investigating HL across different levels of person factors, the raw data obtained from the HLS-Q12 were transformed into logit values using RUMM2030 statistical package [48]. Hence, the analyses were performed with person-location estimates of HL, providing continuous data and interval levels. Furthermore, the demographic variables and variables related to general health, health behaviours and empowerment-related indicators were dichotomised before being entered into the analyses. Differences in HL across person factors were analysed using independent $t$-tests.

A sequential multiple linear regression analysis was performed to further investigate the association between HL and the variables that showed significant differences in HL based on the independent $t$-tests. The general linear regression model requires a continuous outcome variable and assumes normally distributed residuals with constant variance (homoscedasticity) that are independent (residual covariances are zero) and have a mean of zero. To meet the requirement of a continuous outcome variable, the HLS-Q12 person-location estimates from the Rasch modelling were used. There are no requirements for or assumptions related to the independent variables [52].

In the regression analysis, the independent variables 'educational level' and 'general health condition' were dichotomised in the same way as for the $t$-tests, whereas the empowerment-related indicators were treated as categorical with a four-point rating scale. The independent variables were entered in three sequential steps. According to Field [52], variables that are already known to be predictors of the dependent variable should be entered first. As several studies have reported a link between HL and education level [4, 12, 53-57], this variable was introduced first in Model 1. Some studies have reported a link between HL and general health, whereas the link between HL and empowerment has been investigated in people with T2DM only to a small extent. Hence, in Model 1, 
'education level' was entered as the independent variable. In Model 2, the independent variable 'general health condition' was entered in the next step along with 'educational level'. In the final model (Model 3), the independent variables for empowerment-related indicators were added. Hence, it was possible to assess the contribution of each independent variable. Adjusted R squares were used to assess the model fit, whereas a change in an $\mathrm{R}$ square was used to assess the contribution of newly entered independent variables [52]. The standardised $\beta$ coefficient with $p$-value was used to assess the unique contribution of each variable. Initial analyses indicated no violation of the assumptions of multicollinearity, normality, linearity or homoscedasticity. The significance level was set at $5 \%$. It was also investigated whether gender and age could be possible confounders.

Using a sequential multiple regression in SPSS 24 [58], missing data were treated listwise, resulting in an effective sample size of $252-257$.

\section{Results}

In Table 2, the proportion of responses (\%) in each response category of the 4-point rating scale is reported for each HLS-Q12 item. On average, 38\% responded in either category 1 or 2 and perceived the task as (very) difficult.

\section{$\mathrm{HL}$ and demographic variables, general health, diabetes outcome, health behaviours and empowerment-related indicators}

Based on the investigation of HL across the levels of person factors and general health using independent $t$-tests, those with an education level at the university/university college level and those who reported their general health as good had significantly higher HL (person-location estimates of HL) with $p$-values of 0.001 and 0.002 , respectively. No significant differences were observed for the person factors gender, age or HbAlc (Table 3). In addition, there were no significant differences in HL observed across age groups when treating the variable age as categorical (not shown in the table). When investigating HL between those who reported $(n=312)$ their latest HbA1c against those who did not $(n=76)$, it was found that the former group had significantly higher HL ( $p=$ 0.044; not shown in the table). No significant differences in mean values were observed for the health behaviour variables, but those who reported the empowermentrelated indicators as easy had significantly higher HL $(p<0.001$ for all four items).

Those who reported that they had been in contact with a nurse with regard to their health situation during the last year $(n=214)$ had significantly higher HL $(p=0.021)$ than those who had not ( $n=150$; not reported in Table 3$)$.

\section{The association between $\mathrm{HL}$ and education, general health and empowerment-related indicators}

After entering the variables that showed significant differences in HL proficiency (education, self-reported general health and empowerment-related indicators) as independent variables in a sequential multiple linear regression analysis, the variables of the final model (Model 3) explained $33 \%$ of the total variance in $\mathrm{HL}$ as the dependent variable. The empowerment-related indicators explained more of the observed variance in $\mathrm{HL}$ than the other independent variables (change in $\mathrm{R}$ square $=28 \%$; Table 4 ). The items 'take control of one's own health in daily life' and 'participate actively in health communication with health

Table 2 The proportion of responses (\%) in each category of the 4-point rating scale for each HLS-Q12 item

\begin{tabular}{|c|c|c|c|c|c|}
\hline Item no. & Label & Very difficult & Difficult & Easy & Very easy \\
\hline & On a scale from very difficult to very easy, how easy would you say it is to: & & & & \\
\hline 2 & find information on treatments of illnesses that concern you? & 2 & 25 & 64 & 10 \\
\hline 7 & understand what to do in a medical emergency? & 3 & 38 & 53 & 5 \\
\hline 10 & judge the advantages and disadvantages of different treatment options? & 6 & 56 & 35 & 3 \\
\hline 14 & follow the instructions on medication? & 2 & 10 & 72 & 16 \\
\hline 18 & find information on how to manage mental health problems like stress or depression? & 7 & 55 & 33 & 6 \\
\hline 23 & understand why you need health screenings? & 0 & 3 & 68 & 28 \\
\hline 28 & judge if the information on health risks in the media is reliable? & 7 & 60 & 30 & 4 \\
\hline 30 & $\begin{array}{l}\text { decide how you can protect yourself from illness based on advice from family and } \\
\text { friends? }\end{array}$ & 7 & 52 & 37 & 4 \\
\hline 32 & find information on healthy activities, such as exercise, healthy food and nutrition? & 2 & 13 & 70 & 16 \\
\hline 38 & understand information on food packaging? & 10 & 43 & 40 & 7 \\
\hline 43 & judge which everyday behaviour is related to your health? & 1 & 13 & 70 & 16 \\
\hline 44 & make decisions to improve your health? & 2 & 35 & 51 & 11 \\
\hline average & & $4(49 / 12)$ & $34(403 / 12)$ & $52(623 / 12)$ & $11(126 / 12)$ \\
\hline
\end{tabular}

The item number corresponds to the specific item number in the European Health Literacy Survey Questionnaire (HLS-EU-Q47) 
Table 3 Health literacy across levels of person factors, general health, diabetes outcome, health behaviours and empowerment

\begin{tabular}{|c|c|c|c|}
\hline & $n(\%) /$ mean $(s d)^{a}$ & $\mathrm{HL}$ mean $(\mathrm{sd})$ & $P$ value \\
\hline Gender & $n(\%)$ & & \\
\hline Male & $207(53)$ & $0.653(1.43)$ & 0.149 \\
\hline Female & $165(43)$ & $0.881(1.62)$ & \\
\hline Education & $n(\%)$ & & \\
\hline Compulsory comprehensive/upper secondary school & $196(51)$ & $0.599(1.50)$ & 0.001 \\
\hline University/university college & $118(30)$ & $1.195(1.70)$ & \\
\hline \multicolumn{4}{|l|}{ Age } \\
\hline$\leq 73$ years, $n(\%)$ & $187(48)$ & $0.748(1.47)$ & 0.922 \\
\hline$\geq 74$ years, $n(\%)$ & $188(48)$ & $0.763(1.57)$ & \\
\hline General health & $n(\%)$ & & \\
\hline Very good/good/fairly good & $315(82)$ & $0.892(1.55)$ & 0.002 \\
\hline Bad/ very bad & $64(17)$ & $0.235(1.34)$ & \\
\hline \multicolumn{4}{|l|}{$\mathrm{HbA1c}(\%)^{b}$} \\
\hline$\leq 7.0 \%, n(\%)$ & $132(34)$ & $0.953(1.51)$ & 0.319 \\
\hline$\geq 7.1 \%, n(\%)$ & $180(46)$ & $0.778(1.54)$ & \\
\hline \multicolumn{4}{|l|}{ Health behaviour } \\
\hline Physical activity ${ }^{c}$ & $n(\%)$ & & \\
\hline Every or almost every day & $119(31)$ & $0.772(1.46)$ & 0.997 \\
\hline Less activity & $235(61)$ & $0.772(1.52)$ & \\
\hline Health condition not compatible with physical activity & $17(4)$ & & \\
\hline Missing & $17(4)$ & & \\
\hline \multicolumn{4}{|l|}{ Smoking ${ }^{d}$} \\
\hline Daily or now and then & $16(4)$ & $1.491(1.42)$ & 0.052 \\
\hline Never or former smoker & $361(93)$ & $0.733(1.52)$ & \\
\hline Missing & $11(3)$ & & \\
\hline \multicolumn{4}{|l|}{ Alcohol consumption ${ }^{e}$} \\
\hline No & $177(46)$ & $0.740(1.58)$ & 0.728 \\
\hline Yes & $195(50)$ & $0.795(1.47)$ & \\
\hline Missing & $16(4)$ & & \\
\hline \multicolumn{4}{|l|}{ Empowerment-related indicators } \\
\hline Control of own health & $n(\%)$ & & \\
\hline Difficult & $120(31)$ & $0.229(1.53)$ & $<0.001$ \\
\hline Easy & $251(65)$ & $1.044(1.46)$ & \\
\hline Missing & $17(4)$ & & \\
\hline \multicolumn{4}{|l|}{ Implement goals about own health } \\
\hline Difficult & $204(53)$ & $0.425(1.32)$ & $<0.001$ \\
\hline Easy & $166(43)$ & $1.213(1.63)$ & \\
\hline Missing & $18(5)$ & & \\
\hline \multicolumn{4}{|l|}{ Take responsibility for own health } \\
\hline Difficult & $127(33)$ & $0.213(1.32)$ & $<0.001$ \\
\hline Easy & $243(63)$ & $1.075(1.54)$ & \\
\hline Missing & $18(5)$ & & \\
\hline \multicolumn{4}{|l|}{ Participate actively in health communication } \\
\hline Difficult & $111(29)$ & $0.086(1.20)$ & $<0.001$ \\
\hline
\end{tabular}


Table 3 Health literacy across levels of person factors, general health, diabetes outcome, health behaviours and empowerment (Continued)

\begin{tabular}{lll}
\hline & $n(\%) /$ mean $(\mathrm{sd})^{\mathrm{a}}$ & HL mean (sd) \\
\hline Easy & $223(57)$ & $1.105(1.61)$ \\
Missing & $54(14)$ & \\
\hline
\end{tabular}

HL: person-location estimates (logit values) of health literacy by means of the HLS-Q12 of Finbråten et al. [41]. Higher values indicate higher HL

${ }^{a}$ Continuous data: mean (standard deviation [sd]); categorical data: frequencies, $\mathrm{n}$ (percentage [\%])

${ }^{b}$ Highest recommended $\mathrm{HbA} 1 \mathrm{c}$ level in people with T2DM is $7 \%(53 \mathrm{mmol} / \mathrm{mol})$

'How often have you been physically active for at least 30 min during the last 30 days?

${ }^{\mathrm{d}}$ How would you best describe your use of tobacco?

${ }^{\mathrm{e}} \mathrm{How}$ often did you drink alcohol during the last 30 days?

professionals' made the strongest and most significant contributions to the variance in HL in the final model ( $\beta=0.23, p=0.001$ and $\beta=0.28, p<0.001$, respectively), followed by the variable 'education' $(\beta=0.13, p=0.015$; Table 4).

Despite the significant differences in HL between those who reported that they had been in contact with a nurse with regard to their health situation and those who had not, this variable did not make a significant contribution in the regression analysis (not shown in the table). The variables gender and age did not correlate with the dependent variable, nor display any significant contribution to the models (not shown in the table).

\section{Discussion}

On average, 38\% reported that the HL tasks were difficult or very difficult. When measuring HL by means of the HLS-Q12, higher HL was associated with education at the university/university college level, good general health and higher empowerment.
$\mathrm{HL}$ and demographic variables, general health, diabetes outcome, health behaviours and empowerment-related indicators

According to the proportion of responses in each response category, over one-third marked the HL tasks as difficult or very difficult, which implies that health professionals should pay attention to the individual's HL and should adapt their health communication to the appropriate level. In contrast to van der Heide [4] and Hussein, Almajran and Albatineh [53] but in accord with Al Sayah et al. [16] and Vandenbosch et al. [54], no significant differences in HL with regard to age were found. However, the average age of the sample was relatively high, so differences related to age may not have been evident.

Significant differences in HL were found in relation to education. People with T2DM who had completed a university-level education reported a significantly higher HL (as measured by the HLS-Q12) than those with a lower education level, which is similar to the findings of

Table 4 Regression analysis for education, self-reported general health and empowerment-related indicators on health literacy

\begin{tabular}{|c|c|c|c|c|c|c|}
\hline & R square & Adjusted R square & R square change & $p$-value & Standardised $\beta$ coefficient & $p$-value \\
\hline Model $1^{a}$ & 0.030 & 0.026 & 0.030 & 0.005 & & \\
\hline - education & & & & & 0.173 & 0.005 \\
\hline Model $2^{b}$ & 0.067 & 0.060 & 0.037 & 0.002 & & \\
\hline - education & & & & & 0.156 & 0.011 \\
\hline - general health & & & & & 0.194 & 0.002 \\
\hline Model $3^{c}$ & 0.346 & 0.330 & 0.278 & $<0.001$ & & \\
\hline - education & & & & & 0.128 & 0.015 \\
\hline - general health & & & & & 0.027 & 0.625 \\
\hline \multicolumn{7}{|l|}{ - empowerment } \\
\hline - control & & & & & 0.233 & 0.001 \\
\hline - implement goals & & & & & 0.127 & 0.079 \\
\hline - responsibility & & & & & 0.090 & 0.194 \\
\hline - participate actively & & & & & 0.284 & $<0.001$ \\
\hline
\end{tabular}

Note. This table reports results from the sequential multiple regression analysis with health literacy as the dependent variable. The independent variables 'education', 'general health' and empowerment-related indicators were entered in the analysis in three sequential steps. Statistical significance was assumed at $p<0.05$

$\mathrm{a}_{n}=257$

${ }^{b} n=256$

${ }^{c} n=252$ 
previous studies [4, 12, 53-57]. This finding was also supported when using the FCCHL to measure $\mathrm{HL}$ in the same population [11]. According to this finding, nurses and other health professionals should tailor health information to the individual's HL level and their educational level, and they should be prepared to devote more time to explaining relevant health information, using different learning aids and ensuring that the individual thoroughly understands the information. Health professionals should also ensure that individuals have the capacity to use the information to promote their health in everyday life. Regarding the significant association between HL and education, actions aimed at strengthening HL should be implemented as early as primary and secondary school. Such interventions should aim to strengthen reading and writing skills, strengthen knowledge related to health issues and the determinants of health, strengthen competence in the critical assessment of different sources of health information and strengthen knowledge regarding where to find evidence-based health information.

Those with a higher HL reported significantly better general health than those with lower HL estimates. However, only $4 \%$ of the variance in HL was explained by general health condition. Whether low HL could result in worse health or whether the opposite occurs is unclear. If low HL causes worse health, adapting health information to the individual's HL is important to avoid a negative impact on health. Strengthening HL could improve an individual's health, and thus a particular effort should be made to develop HL in people with T2DM. This is also supported by Al Sayah et al. [12], who called for studies investigating whether such interventions could lead to improvements in health.

It was also found that those who had been in contact with a registered nurse regarding their health situations had significantly higher HL. In Norway, people with T2DM are usually offered a follow-up by their regular general practitioners [45]. Those who are offered additional follow-ups with registered nurses may receive more comprehensive information and information better adapted to their needs. Registered nurses may conduct longer consultations than general practitioners due to time constraints, and thus they have time to adapt and to explain the information more thoroughly. This is potentially supported by Tshiananga [59], who found that nurse-led follow-ups and diabetes education were associated with improved glycaemic control. Thus, it could be recommended that people with T2DM should be offered follow-ups with registered nurses who are educated in diabetes treatment and health communication in addition to the follow-ups provided by general practitioner. However, many nurses have limited knowledge related to HL $[60,61]$, which could affect the learning outcomes of diabetes education and self-management in people with T2DM. Hence, nursing education should include a greater emphasis on HL as well as how health communication could be better adapted to people's HL levels.

No significant differences were found in HL related to HbA1c, which is in accord with Lee et al. [57], Al Sayah et al. [16] and Finbråten et al. [11] (the latter using the FCCHL in the same population) but in contrast to van der Heide et al. [4], Powell et al. [5], Schillinger et al. [7], Tang et al. [8] and Cavanaugh et al. [9]. However, significant differences were found in HL between those reporting and those not reporting their latest HbA1c levels. The reason for people not reporting this value is uncertain. One reason could be that they do not know their latest HbA1c levels. Hence, it is possible that there is an association between $\mathrm{HL}$ and knowing the HbA1c level. The findings confirm the claim put forward by $\mathrm{Al}$ Sayah et al. [13] and Bailey et al. [14] that the association between $\mathrm{HL}$ and HbA1c is inconsistent. This inconsistency may be due to HL being measured using different instruments. All the studies mentioned $[4,5,7-9,16]$ with the exception of Lee et al. [57] and Finbråten et al. [11] measured HL using instruments that were limited to the functional HL level. Another explanation might be different operationalisations of the variable HbAlc. When treating $\mathrm{HbA} 1 \mathrm{c}$ as a dichotomous variable, van der Heide et al. [4] did not find a significant difference in HL.

Despite the association between HL and self-reported general health, there was no association between HL and health behaviours. The absence of an association between HL and both smoking behaviours and alcohol consumption is in line with the findings of Friis et al. [21]. However, the association between HL and physical activity, as described by Friis et al. [21] and van der Heide et al. [4], was not supported by this study. Measuring HL using the FCCHL, Shin and Lee [62] did not find any significant direct effect of HL on physical activity in elderly people with diabetes. The average age in the sample was quite high. Hence, T2DM in the sample could be linked more to age than to health behaviours. The association between HL and health behaviours should be further explored in younger individuals with T2DM. Since the study was initiated, the recommendation for physical activity has changed from $30 \mathrm{~min}$ of physical activity per day to $150 \mathrm{~min}$ of physical activity each week [63]. However, dividing $150 \mathrm{~min}$ by 5 days equals 30 min 5 days per week. As this change can be considered quite small, it is not expected to influence the results of this study.

Theoretically, HL has been linked to empowerment [2, 32]. A significant association between HL and all four empowerment-related indicators was found. A relationship between personal empowerment and HL was also identified by Wang et al. [27]. The empowerment- 
related indicators also contributed the most to the variance in $\mathrm{HL}$ when performing the regression analysis. If Nutbeam's theory [32] is assumed to be correct and thus higher HL implies higher empowerment, strengthening HL might lead to greater empowerment. Hence, to enhance empowerment in people with T2DM, nurses and other health professionals should strengthen their HL, such as by providing valid and reliable health information and guiding the individuals to the actual sources of the information. Furthermore, nurses and other health professionals should guide individuals in evaluating the advantages and disadvantages of the different treatment options and should facilitate their active participation in health communication. In addition, they should enable individuals to take control of their own health in their daily lives by providing adapted health information. The association between $\mathrm{HL}$ and taking control of one's own health could also confirm the theoretical association between HL and empowerment, as 'control' is a central part of the definition of individual empowerment. However, higher HL does not necessarily entail empowerment [1]. Schulz and Nakamoto [1] pointed out that mismatches of these two factors can have dangerous consequences, as emphasising a high degree of empowerment without adequate knowledge and a high level of HL may increase the risk of making inexpedient health choices.

By defining empowerment as a process, Lee et al. [57] claimed that there is a direct pathway from empowerment to HL. Hence, if the individual's active participation and involvement in health communication is facilitated, it may also strengthen HL. It is important that nurses and other health professionals facilitate this involvement by using language that is adapted to the patient's HL level and framework of understanding. This is in accord with Engström, Leksell, Johansson and Gudbjörnsdottir [64], who found that some health information was difficult to understand due to the use of jargon and that people wanted the information to be tailored to their needs. Engström et al. [64] also found that most people with diabetes (both Types 1 and 2) wanted to participate in shared decision making. Hence, nurses and other health professionals should ask the patients about their preferences and should invite them to participate in a dialogue regarding their health and the requirements associated with living with T2DM.

The final regression model explained $33 \%$ of the variance, which means that other factors also contributed to the variance in HL. In light of the definition provided by Sørensen et al. [2], it is reasonable to assume that factors such as motivation, diabetes knowledge and general literacy may contribute to the variance in HL. Additional factors, such as self-efficacy, may also contribute to the variance in HL. There may also be person factors other than those mentioned that contribute to the variance.

\section{Methodological considerations}

The sample was drawn from the member list of the NDA. Hence, the sample might not be representative of the entire population of people with T2DM, as members of such an organisation may be better informed and motivated in managing their chronic disease than nonmembers. However, it was difficult to recruit nonmembers as we were not allowed to use Norwegian Patient Registry as a sampling frame. In addition, the mean age of the sample was quite high and was higher than the average age in the member list. Consequently, the results may be considered a reflection of older adults with T2DM.

We do not have access to information about age and educational level in Norwegians with T2DM not being members of the NDA. However, in a study describing the incidence of T2DM in Norway [44] from 2009 to 2014, people aged 55 and older constituted $75 \%$ of all individuals newly diagnosed with T2DM. Ruiz et al. [44] reported that about the half of the individuals newly diagnosed with T2DM had completed education at upper secondary school-level, which is similar to our study. Further, Ruiz et al. [44] reported that just below one fifth had completed higher education, which is however in contrast with our sample, where $30 \%$ had such education.

Despite the high average age in our study sample, the majority of the respondents considered their health as good or even very good. However, in Norway there is not unusual that elderly people rate their health as good. In fact, according to Statistics Norway [65], 60\% of Norwegians 80 years old rate their health as good or very good. The associations between HL and general health, health behaviours and empowerment should be further explored in younger people with T2DM. According to Statistics Norway [66], 11\% of the entire population includes daily smokers. Hence, there is a risk of a response bias in the study because only $4 \%$ reported being a smoker.

Responding to self-administered measures could be quite challenging for elderly people and for those with limited HL, as it requires reading and reading comprehension abilities. However, during cognitive interviews, the participants reported that the items were clearly stated and easy to understand. Advantages of using paper- and-pencil questionnaire are that there are lower risk for interviewer bias and that the respondents answering according to what they think is expected [67].

The sample size was rather small, which might lower the generalisability of the findings. However, assuming $80 \%$ power, the number of independent variables and a small to medium effect size, the sample size could be considered sufficient $[52,68]$.

To ensure the plausibility of the interpretations of the scores obtained from the HLS-Q12 for people with T2DM, the psychometric properties of the scale were 
assessed. Applying the Rasch model analysis and CFA, the HLS-Q12 was found to have acceptable psychometric properties for people with T2DM. These findings are similar to those of Finbråten et al. [42], who validated the HLS-Q12 in the Norwegian population. However, in contrast to Finbråten et al. [42], a discrepancy between the fit indexes CFI and RMSEA was found, which suggested a good and a relatively bad fit, respectively. This discrepancy was further explored by comparing estimates obtained from ML and DWLS, which displayed quite similar results. Moreover, the LISREL output did not suggest any modification indices. However, Brown [69] claimed that a high value of RMSEA may be of less concern if other GOF indexes suggest acceptable model fit. Altogether, the HLS-Q12 showed several strengths, as the data displayed a good fit to the unidimensional Rasch model, which implies that all requirements of the fundamental measurement were met [70]. Hence, the HLS-Q12 could be used as a valid and reliable scale for measuring HL in people with T2DM in relation to different health settings. However, the GOF indexes should be further explored in future studies. The HLS-Q12 has thus far been validated for people with T2DM and in the Norwegian population, but the psychometric properties of the instrument should be further assessed in other populations and across different languages and cultures.

\section{Conclusions}

When applying the HLS-Q12 to measure HL in people with T2DM, it was found that a higher HL was associated with education at the university/university college level, good self-reported general health and higher empowerment-related indicators. Nurses and other health professionals should be aware that people have different levels of HL and should pay particular attention to the prerequisites for dealing with health information among those with less education and worse self-reported health. Furthermore, the health information should be adapted to the individual's HL to support the individual's active participation in diabetes management and to enable individuals to take control of their own health in their daily lives. No evidence of an association between HL and glycaemic control nor between HL and health behaviours was found.

The association between HL and health behaviours should be further investigated, especially in younger people with T2DM. Other factors that could contribute to the variance in $\mathrm{HL}$ should also be investigated.

\section{Abbreviations}

CFA: Confirmatory factor analysis; CFI: Comparative fit index; Cl: Confidence interval; DWLS: Diagonally Weighted Least Squares; FCCHL: Functional, Communicative, and Critical Health Literacy scale; GOF: Goodness-of-fit; HbA1c: Glycated haemoglobin; HL: Health literacy; HLS-EU-Q47: European Health Literacy Survey Questionnaire; ML: Maximum Likelihood;

NDA: Norwegian Diabetes Association; RMSEA: Root-mean-squared error of approximation; SRMR: Standardised root mean square residual; T2DM: Type 2 diabetes

\section{Acknowledgements}

The authors thank Jari Appelgren for guidance during the multiple regression analysis.

\section{Authors' contributions}

All authors (HSF, ØG, GN, KSP, AT and BWL) contributed to the study design. HSF performed the data analyses under supervision from $\varnothing \mathrm{G}$ and Jari Appelgren. HSF wrote the draft of the manuscript. All authors (HSF, $\varnothing \mathrm{G}, \mathrm{GN}$, $\mathrm{KSP}, \mathrm{AT}$ and $\mathrm{BWL}$ ) contributed to reading, revising and approving the final manuscript.

\section{Funding}

The data collection was funded by the Norwegian Nurses' Organisation [grant number 14/0023] and the Inland Norway University of Applied Sciences [grant number 2013/1565].

\section{Availability of data and materials}

The dataset used and analysed during the current study is available from the corresponding author upon reasonable request.

\section{Ethics approval and consent to participate}

This study was approved by the Norwegian Social Science Data Service (NSD), ref. 38917. In Norway, all research projects processing personal data must apply for an approval from NSD. The NSD do an overall assessment whether collecting, registering, storing, sharing and/or publishing personal data in the research project meet the requirements of data protection legislation and are in line with ethical guidelines. On basis of this assessment, NSD decides whether it is necessary to receive an additional approval from the Regional Commitees for Medical and Health Research Ethics. According to NSD, our study did not require ethics approval from an ethics committee. Subject participation was voluntary, and questionnaires were completed anonymously. We considered returning a completed questionnaire as consent to participate in the project. This procedure for obtaining informed consent was stated in the information letter that was sent to the participants, and this procedure was also approved by the NSD.

Consent for publication

Not applicable.

\section{Competing interests}

The authors declare that they have no competing interests.

\section{Author details}

${ }^{1}$ Department of Health and Nursing Sciences, Faculty of Social and Health Sciences, Inland Norway University of Applied Sciences, PO Box 400, N-2418 Elverum, Norway. ${ }^{2}$ Department of Health Sciences, Faculty of Health, Science and Technology, Nursing science, Karlstad University, SE-65188 Karlstad, Sweden. ${ }^{3}$ Norwegian Centre for Science Education, Faculty of Mathematics and Natural Sciences, University of Oslo, PO Box 1106, Blindern, N-0317 Oslo, Norway. ${ }^{4}$ Department of Nursing and Health Promotion, Faculty of Health Sciences, OsloMet - Oslo Metropolitan University, PO Box 4, St Olavs plass, N-0130 Oslo, Norway.

\section{Received: 3 October 2019 Accepted: 24 January 2020}

\section{References}

1. Schulz PJ, Nakamoto K. Health literacy and patient empowerment in health communication: the importance of separating conjoined twins. Patient Educ Couns. 2013;90(1):4-11.

2. Sørensen K, Van den Broucke S, Fullam J, Doyle G, Pelikan J, Slonska Z, Brand $\mathrm{H}$. Health literacy and public health: a systematic review and integration of definitions and models. BMC Public Health. 2012;12(1):1-13.

3. Johnson A. Health literacy, does it make a difference? Aust J Adv Nurs. 2014 31(3):39.

4. van der Heide I, Uiters E, Rademakers J, Struijs JN, Schuit AJ, Baan CA Associations among health literacy, diabetes knowledge, and self- 
management behavior in adults with diabetes: results of a Dutch crosssectional study. J Health Commun. 2014;19(Suppl 2):115-31.

5. Powell CK, Hill EG, Clancy DE. The relationship between health literacy and diabetes knowledge and readiness to take health actions. Diabetes Educ. 2007;33(1):144-51.

6. Hahn EA, Burns JL, Jacobs EA, Ganschow PS, Garcia SF, Rutsohn JP, Baker DW. Health literacy and patient-reported outcomes: a cross-sectional study of underserved English-and Spanish-speaking patients with type 2 diabetes. J Health Commun. 2015;20(Suppl 2):4-15.

7. Schillinger D, Grumbach K, Piette J, Wang F, Osmond D, Daher C, Palacios J, Sullivan GD, Bindman AB. Association of health literacy with diabetes outcomes. JAMA. 2002;288(4):475-82.

8. Tang YH, Pang SM, Chan MF, Yeung GS, Yeung VT. Health literacy, complication awareness, and diabetic control in patients with type 2 diabetes mellitus. J Adv Nurs. 2008;62(1):74-83.

9. Cavanaugh K, Huizinga MM, Wallston KA, Gebretsadik T, Shintani A, Davis D, Gregory RP, Fuchs L, Malone R, Cherrington A, et al. Association of numeracy and diabetes control. Ann Intern Med. 2008;148(10):737-46.

10. Ishikawa H, Takeuchi T, Yano E. Measuring functional, communicative, and critical health literacy among diabetic patients. Diabetes Care. 2008;31(5): 874-9.

11. Finbråten HS, Guttersrud $\varnothing$, Nordström G, Pettersen KS, Trollvik A, WildeLarsson B. Validating the functional, communicative and critical health literacy scale using Rasch modeling and confirmatory factor analysis. J Nurs Meas. 2018;26(2):341-63.

12. Al Sayah F, Qiu W, Johnson JA. Health literacy and health-related quality of life in adults with type 2 diabetes: a longitudinal study. Qual Life Res. 2016; 25(6):1487-94

13. Al Sayah F, Majumdar SR, Williams B, Robertson S, Johnson JA. Health literacy and health outcomes in diabetes: a systematic review. J Gen Intern Med. 2013;28(3):444-52.

14. Bailey SC, Brega AG, Crutchfield TM, Elasy T, Herr H, Kaphingst K, Karter AJ, Moreland-Russell S, Osborn CY, Pignone M. Update on health literacy and diabetes. Diabetes Educ. 2014;40(5):581-604.

15. Berkman ND, Sheridan SL, Donahue KE, Halpern DJ, Crotty K. Low health literacy and health outcomes: an updated systematic review. Ann Intern Med. 2011;155(2):97.

16. Al Sayah F, Majumdar SR, Johnson JA. Association of inadequate health literacy with health outcomes in patients with type 2 diabetes and depression: secondary analysis of a controlled trial. Can J Diabetes. 2015; 39(4):259-65.

17. Boren SA. A review of health literacy and diabetes: opportunities for technology. J Diabetes Sci Technol. 2009;3(1):202-9.

18. Caruso R, Magon A, Baroni I, Dellafiore F, Arrigoni C, Pittella F, Ausili D. Health literacy in type 2 diabetes patients: a systematic review of systematic reviews. Acta Diabetol. 2018;55(1):1-12.

19. International Diabetes Federation. IDF Diabetes Atlas. 2017. https://www.idf. org/our-activities/advocacy-awareness/resources-and-tools/134:idf-diabetesatlas-8th-edition.html. Accessed 12 Feb 2019.

20. World Health Organization (WHO). Diabetes. http://www.who.int/ mediacentre/factsheets/fs312/en/. Accessed 20 Feb 2019.

21. Friis K, Vind BD, Simmons RK, Maindal HT. The relationship between health literacy and health behaviour in people with diabetes: a Danish populationbased study. J Diabetes Res. 2016;2016:1-7.

22. Fernandez DM, Larson JL, Zikmund-Fisher BJ. Associations between health literacy and preventive health behaviors among older adults: findings from the health and retirement study.(Report). BMC Public Health. 2016;16(1):596.

23. Levin-Zamir D, Baron-Epel OB, Cohen V, Elhayany A. The association of health literacy with health behavior, socioeconomic indicators, and selfassessed health from a national adult survey in Israel. J Health Commun 2016;21(Suppl 2):61-8.

24. Geboers B, Reijneveld SA, Jansen CJM, de Winter AF. Health literacy is associated with health behaviors and social factors among older adults: results from the LifeLines cohort study. J Health Commun. 2016:1-9.

25. Al Sayah F, Johnson ST, Vallance J. Health literacy, pedometer, and selfreported walking among older adults. Am J Public Health. 2016;106(2): 327-33.

26. Jayasinghe UW, Harris MF, Parker SM, Litt J, van Driel M, Mazza D, Del Mar C, Lloyd J, Smith J, Zwar N. The impact of health literacy and life style risk factors on health-related quality of life of Australian patients. Health Qual Life Outcomes. 2016;14(1):68.
27. Wang R-H, Hsu H-C, Lee Y-J, Shin S-J, Lin K-D, An L-W. Patient empowerment interacts with health literacy to associate with subsequent self-management behaviors in patients with type 2 diabetes: a prospective study in Taiwan. Patient Educ Couns. 2016;99(10):1626-31.

28. Bagnasco A, Di Giacomo P, Da Rin Della Mora R, Catania G, Turci C, Rocco G, Sasso L. Factors influencing self-management in patients with type 2 diabetes: a quantitative systematic review protocol. J Adv Nurs. 2014;70(1): 187-200.

29. World Health Organization (WHO): Health promotion glossary. 1998. http:// www.who.int/healthpromotion/about/HPR\%20Glossary\%201998.pdf?ua=1. Accessed 28 June 2018

30. Schiavo R. Health communication: from theory to practice. 2nd ed. San Francisco: Jossey-Bass; 2014.

31. Paasche-Orlow MK, Schillinger D, Weiss BD, Bickmore T, Cabral H, Chang P, Bailey SC, Dewalt DA, Fernandez A, Fransen M. Health literacy and power. Health Lit Res Pract. 2018;2(3):e132-3.

32. Nutbeam D. Health literacy as a public health goal: a challenge for contemporary health education and communication strategies into the $21 \mathrm{st}$ century. Health Promot Int. 2000;15(3):259-67.

33. Nutbeam D. The evolving concept of health literacy. Soc Sci Med. 2008; 67(12):2072-8.

34. Parker RM, Baker DW, Williams MV, Nurss JR. The test of functional health literacy in adults: a new instrument for measuring patients' literacy skills. J Gen Intern Med. 1995;10(10):537-41.

35. Baker DW, Williams MV, Parker RM, Gazmararian JA, Nurss J. Development of a brief test to measure functional health literacy. Patient Educ and Couns. 1999;38(1):33-42.

36. Davis TC, Long SW, Jackson RH, Mayeaux E, George RB, Murphy PW, Crouch MA. Rapid estimate of adult literacy in medicine: a shortened screening instrument. Fam Med. 1993;25(6):391-5.

37. Chew LD, Bradley KA, Boyko EJ. Brief questions to identify patients with inadequate health literacy. Fam Med. 2004;36(8):588-94.

38. HLS-EU Consortium. Comparative report of health literacy in eight EU member states. European health Literacy Survey HLS-EU 2012.

39. Sørensen K, Van den Broucke S, Pelikan JM, Fullam J, Doyle G, Slonska Z, Kondilis B, Stoffels V, Osborne RH, Brand H. Measuring health literacy in populations: illuminating the design and development process of the European health literacy survey questionnaire (HLS-EU-Q). BMC Public Health. 2013;13(1):948

40. Finbråten HS, Pettersen KS, Wilde-Larsson B, Nordström G, Trollvik A Guttersrud $\varnothing$. Validating the European health literacy survey questionnaire in people with type 2 diabetes. Latent trait analyses applying multidimensional Rasch modelling and confirmatory factor analysis. J Adv Nurs. 2017;73(11):2730-44.

41. Huang Y-J, Chen C-T, Lin G-H, Wu T-Y, Chen S-S, Lin L-F, Hou W-H, Hsieh CL. Evaluating the European health literacy survey questionnaire in patients with stroke: a latent trait analysis using Rasch modeling. Patient. 2018;11(1): 83-93.

42. Finbråten HS, Wilde-Larsson B, Nordström G, Pettersen KS, Trollvik A, Guttersrud $\varnothing$. Establishing the HLS-Q12 short version of the European health literacy survey questionnaire. BMC Health Serv Res. 2018;18(506):1-17.

43. Finbråten HS. Measuring health literacy - evaluating psychometric properties of the HLS-EU-Q47 and the FCCHL, suggesting instrument refinements and exploring health literacy in people with type 2 diabetes and in the general Norwegian population. Karlstad: Karlstad University Studies; 2018

44. Ruiz PLD, Stene LC, Bakken IJ, Håberg SE, Birkeland KI, Gulseth HL Decreasing incidence of pharmacologically and non-pharmacologically treated type 2 diabetes in Norway: a nationwide study. Diabetologia. 2018; 61(11):2310-8

45. The Norwegian Directorate of Health. Nasjonal faglig retningslinje for diabetes [National professional guideline for diabetes]. 2017. https:// helsedirektoratet.no/retningslinjer/diabetes. Accessed 28 June 2018.

46. Rasch G. Probabilistic models for some intelligence and attainment tests. Expanded ed. Chicago: University of Chicago Press; 1960.

47. Masters GN. A Rasch model for partial credit scoring. Psychometrika. 1982; 47(2):149-74.

48. Andrich D, Sheridan B, Luo G. Rasch Unidimensional Measurement Model. RUMM2030 (Software). RUMM Laboratory Pty Ltd.; 2003.

49. Jöreskog K, Sörbom D. LISREL 9.3 software. Skokie: Scientific Software International, Inc; 2017. 
50. Anderson RM, Funnell MM, Fitzgerald JT, Marrero DG. The diabetes empowerment scale: a measure of psychosocial self-efficacy. Diabetes Care. 2000;23(6):739-43.

51. Schulz PJ, Nakamoto K. "Bad" Literacy, the Internet, and the Limits of Patient Empowerment. In: AAAI Spring Symposium: Al and Health Communication; 2011.

52. Field A. Discovering statistics using IBM SPSS statistics. 4th ed. Los Angeles: SAGE; 2013.

53. Hussein SH, Almajran A, Albatineh AN. Prevalence of health literacy and its correlates among patients with type II diabetes in Kuwait: a population based study. Diabetes Res Clin Pract. 2018;141:118-25.

54. Vandenbosch J, Van den Broucke S, Schinckus L, Schwarz P, Doyle G, Pelikan J, Muller I, Levin-Zamir D, Schillinger D, Chang P. The impact of health literacy on diabetes self-management education. Health Educ J. 2018;77(3): 349-62.

55. Lai AY, Ishikawa H, Kiuchi T, Mooppil N, Griva K. Communicative and critical health literacy, and self-management behaviors in end-stage renal disease patients with diabetes on hemodialysis. Patient Educ Couns. 2013;91(2):221-7.

56. Heijmans M, Waverijn G, Rademakers J, van der Vaart R, Rijken M. Functional, communicative and critical health literacy of chronic disease patients and their importance for self-management. Patient Educ Couns. 2015:98(1):41-8

57. Lee Y-J, Shin S-J, Wang R-H, Lin K-D, Lee Y-L, Wang Y-H. Pathways of empowerment perceptions, health literacy, self-efficacy, and self-care behaviors to glycemic control in patients with type 2 diabetes mellitus. Patient Educ Couns. 2016;99(2):287-94.

58. IBM Corporation. SPSS version 24. 2016

59. Tshiananga JKT, Kocher S, Weber C, Erny-Albrecht K, Berndt K, Neeser K. The effect of nurse-led diabetes self-management education on glycosylated hemoglobin and cardiovascular risk factors: a meta-analysis. Diabetes Educ. 2012;38(1):108-23.

60. Macabasco-O'Connell A, Fry-Bowers EK. Knowledge and perceptions of health literacy among nursing professionals. J Health Commun. 2011; 16(Suppl 3):295-307.

61. Rajah R, Ahmad Hassali MA, Jou LC, Murugiah MK. The perspective of healthcare providers and patients on health literacy: a systematic review of the quantitative and qualitative studies. Perspect Public Health. 2017;138(2): $122-32$

62. Shin KS, Lee EH. Relationships of health literacy to self-care behaviors in people with diabetes aged 60 and above: empowerment as a mediator. J Adv Nurs. 2018;74:2363-72.

63. World Health Organization (WHO). Global Strategy on Diet, Physical Activity and Health. Recommended levels of physical activity for adults aged 18-64 years. http://www.who.int/dietphysicalactivity/factsheet_adults/en/. Accessed 12 Feb 2019.

64. Engström MS, Leksell J, Johansson U-B, Gudbjörnsdottir S. What is important for you? A qualitative interview study of living with diabetes and experiences of diabetes care to establish a basis for a tailored patientreported outcome measure for the Swedish National Diabetes Register. BMJ Open. 2016:6(3):e010249.

65. Statistics Norway. State of health. 2018. https:/www.ssb.no/helse/artikler-ogpublikasjoner/over-halvparten-av-oss-blir-over-80-ar-og-stadig-sprekere. Accessed 18 Sept 2019.

66. Statistics Norway. Smoking habits. 2018. https:/www.ssb.no/en/helse/ statistikker/royk. Accessed 28 June 2018.

67. Polit DF, Beck CT. Nursing research: generating and assessing evidence for nursing practice. Philadelphia: Wolters Kluwer Health Lippincott Williams \& Wilkins; 2012.

68. Knofczynski GT, Mundfrom D. Sample sizes when using multiple linear regression for prediction. Educ Psychol Meas. 2008;68(3):431-42.

69. Brown TA. Confirmatory factor analysis for applied research. New York: Guilford Publications; 2015

70. Kreiner S. The Rasch model for dichotomous items. In: Christensen KB, Kreiner S, Mesbah M, editors. Rasch models in health. Hoboken: John Wiley \& Sons Inc.; 2013. p. 5-25.

\section{Publisher's Note}

Springer Nature remains neutral with regard to jurisdictional claims in published maps and institutional affiliations.

\section{Ready to submit your research? Choose BMC and benefit from:}

- fast, convenient online submission

- thorough peer review by experienced researchers in your field

- rapid publication on acceptance

- support for research data, including large and complex data types

- gold Open Access which fosters wider collaboration and increased citations

- maximum visibility for your research: over $100 \mathrm{M}$ website views per year

At BMC, research is always in progress.

Learn more biomedcentral.com/submissions 